\title{
AN INTRODUCTION \\ TO ALGOL 68 \\ THROUGH PROBLEMS
}

A. LEARNER

Department of Pure Mathematics

Queen Mary College

A. J. POWELL

Department of Computer Science

Queen Mary College

M 
ISBN 978-1-349-02228-1 ISBN 978-1-349-02226-7 (eBook)

DOI 10.1007/978-1-349-02226-7

(C) A. Learner and A. J. Powell 1974

Reprint of the original edition 1974

All rights reserved. No part of this publication may be reproduced or transmitted in any form or by any means without permission.

First published 1974 by

THE MACMILLAN PRESS LTD

London and Basingstoke Associated companies in New York Dublin Melbourne Johannesburg and Madras

SBN 333166205

Typeset in Great Britain by

PREFACE LIMITED

Salisbury, Wilts

The paperback edition of this book is sold subject to the condition that it shall not, by way of trade or otherwise, be lent, re-sold, hired out, or otherwise circulated without the publisher's prior consent in any form of binding or cover other than that in which it is published and without a similar condition including this condition being imposed on the subsequent purchaser. 


\section{Contents}

Preface $v$

1 Computers and their Languages 1

2 Summing a Series: Iteration 5

3 Traversing a Maze: Multiple Values 23

4 Calendars: Procedures 36

5 Growing a Tree: References 55

6 Sorting a File: Transput 71

7 Problems Re-visited: Advanced Features $\quad 88$

Appendix I. Standard Operations and Functions 100

$\begin{array}{lll}\text { Appendix II. A BNF for Algol } 68 & 105\end{array}$

$\begin{array}{lll}\text { Appendix III. Implementations } & 109\end{array}$

$\begin{array}{ll}\text { Solutions to Exercises } & 111\end{array}$

$\begin{array}{ll}\text { Index } & 122\end{array}$ 


\section{Preface}

This book is intended to serve the beginner as both an introduction to programming and an introduction to the programming language Algol 68. The contents of the book form the basis of the programming component of a first-year course in computer science at Queen Mary College, University of London. No previous knowledge of programming is required but some acquaintance with elementary mathematical terminology and notation is assumed. Those familiar with other programming languages should also find this text of use as an introduction to Algol 68.

The algorithmic approach to solution of problems has been used both to illustrate program construction and to motivate the introduction of the various features in the language. This has allowed the majority of topics to be introduced and elaborated without too much artificiality. Some minor details have been relegated to exercises, for which complete solutions are given. However, it is not intended as a comprehensive treatment of Algol 68, which can be found in $\mathrm{C}$. $\mathrm{H}$. Lindsey and S. G. van der Meulen, Informal Introduction to Algol 68, North-Holland, Amsterdam (1971).

All the programs, sections of programs and solutions to exercises are written to conform to the standard definition of Algol 68 and all of them have been validated by testing with the Algol 68R compiler on an ICL 1904S at Queen Mary College. The programs are written so that only minor modifications are needed for this purpose, and the method of conversion is explained in Appendix III. The language is as defined in the IFIP authorised Revised Report on the Algorithmic Language $A L G O L$ 68, Springer-Verlag, New York (1974). The style of programming is deliberately explicit and designed more for student perusal than for efficiency.

BNF (Backus-Naur Form) is used to define the syntax, serves as an adjunct to the text and helps to avoid the description of minutiae of the recipe-book approach. There is no pretension that this is a definition of Algol 68 but it should enable the novice to check definitions and verify the syntax of programs. It is not suggested that everything which is correct with respect to this BNF is necessarily a correct Algol 68 program.

The algorithmic approach and the use of BNF have been used effectively in the teaching of Algol 68 to beginners.

We gratefully acknowledge the helpful criticism of Professor J.S. Rohl, who read draft versions of the book, and also thank the Queen Mary College Computer Centre for their cooperation in running Algol 68 programs, and in particular for the introduction of a 'cafeteria' service with an instant turn-round.

London 1974

A. LEARNER

A. J. POWELL 